\title{
A Visita Domiciliária Realizada pelo Agente Comunitário de Saúde sob a ótica de Adultos e Idosos
}

\section{The Home Visit Performed by the Community Health Agent from the Perspective of Adults and Elderly}

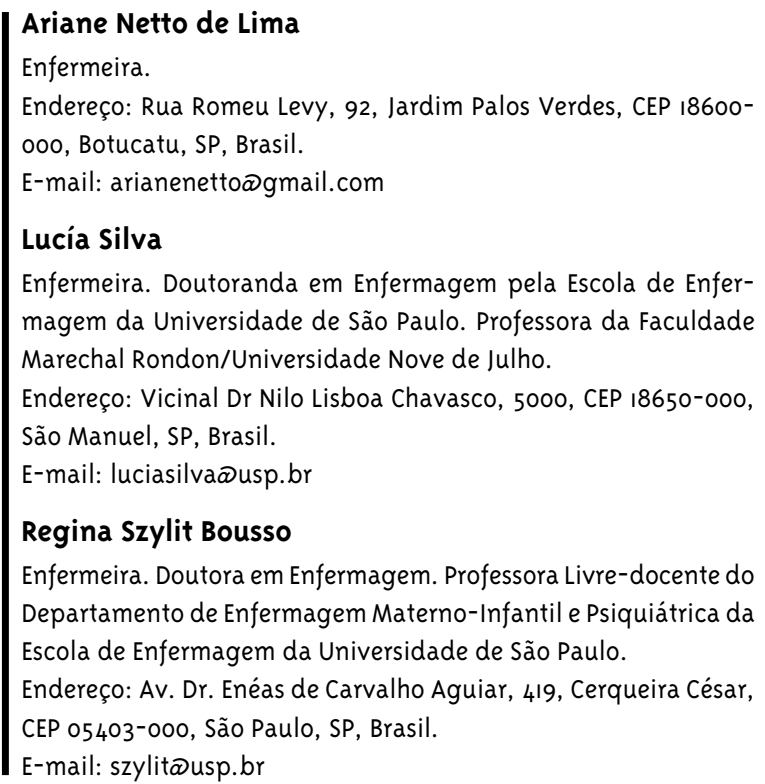

E-mail: szylitœusp.br

\section{Resumo}

A visita domiciliária constitui o principal instrumento de trabalho dos agentes comunitários na Estratégia Saúde da Família. O objetivo deste estudo foi descrever a percepção de adultos e idosos em relação à visita domiciliária realizada pelo agente comunitário de saúde. Como referencial metodológico foi utilizada a abordagem qualitativa embasada em algumas figuras metodológicas do Discurso do Sujeito Coletivo. Os dados foram coletados em maio de 2007, em uma Unidade de Saúde da Família de Botucatu-SP, por meio de formulário sociodemografico e entrevista semiestruturada aplicada a 14 usuários. A análise dos dados permitiu identificar dois temas: "Sentimentos e percepções em relação à visita e ao agente comunitário" e "O reconhecimento das ações do agente comunitário". Apesar de os entrevistados sentirem-se satisfeitos e gratos diante da visita, o fato de perceberem a frequência mensal como insuficiente e de alegarem desconhecer o conteúdo das anotações realizadas pelo agente no momento da visita sinalizam a necessidade de o enfermeiro investir de maneira mais intensa em atividades educativas junto a esses profissionais, priorizando questões que envolvem os processos de comunicação. Acredita-se que com essa medida será possível otimizar, qualitativamente, a realização da atividade.

Palavras-chave: Visita domiciliar; Programa saúde da família; Pesquisa qualitativa; Idoso. 


\section{Abstract}

Home visits are the main working tool for community agents in the Family Health Strategy. The objective of this study was to describe the perception of adults and elderly about the home visit performed by the community health agent. The employed methodology was the qualitative approach based on some methodological procedures of the Discourse of the Collective Subject. Data were collected in May 2007 at a Family Health Unit of the city of Botucatu, state of São Paulo, by means of a socio-demographic form and a semi-structured interview conducted with 14 users. Data analysis identified two themes: "Feelings and perceptions in relation to the visit and the community agent" and "The recognition of the community agent's actions." Although the interviewees feel satisfied with and grateful for the visit, they believe that the frequency is insufficient and ignore the contents of the notes made by the agent during the visit, which indicate that nurses must invest in educational activities with these professionals, prioritizing issues involving communication processes. It is believed that with this, it will be possible to optimize, qualitatively, this activity.

Keywords: Home Visit; Family Health Program; Qualitative Research; Aged.

\section{Introdução}

Nos últimos anos, a Estratégia Saúde da Família (ESF) tem tido grande importância para a diminuição dos índices de morbimortalidade no Brasil, constituindo-se uma modalidade de atenção permanente para a consolidação do Sistema Único de Saúde (SUS). Com sua expansão, o controle dos agravos, bem como as ações de promoção e de prevenção à saúde, podem ser realizados por meio das visitas domiciliárias das equipes de saúde, sobretudo aquelas realizadas pelos agentes comunitários de saúde, já que esses são os componentes da equipe que permanecem em contato mais frequente com as famílias no domicílio.

Trata-se de um modelo para reorganização da assistência à saúde, visando o bem-estar físico, mental e social do ser humano e a transformação social (Sisson, 2007), pautada nos princípios da universalidade, integralidade, equidade, regionalização e hierarquização, descentralização e participação popular.

Um de seus grandes potenciais é a capacidade de a equipe oferecer suporte e fortalecer as famílias para lidarem com situações críticas, como o envelhecimento, por exemplo, buscando reduzir a sobrecarga e o sofrimento (Silva e col., 2009).

Essa estratégia possibilita estreito vínculo entre a equipe de saúde e a comunidade, já que é responsável por limitado número de famílias em determinada área de abrangência, o que facilita o conhecimento dos indivíduos, suas famílias e suas histórias de vida (Silva, 2007).

De acordo com a Portaria $\mathrm{n}^{0} 1886$ do Ministério da Saúde (Brasil, 1997), para a implantação da estratégia, deve-se ter uma clientela de, no máximo, 4.500 pessoas e uma equipe composta basicamente de um médico, um enfermeiro, auxiliares de enfermagem e Agentes Comunitários de Saúde (ACS).

Os ACS são pessoas selecionadas dentro do próprio contexto comunitário para atuar junto à população. Cada um deles é responsável por de 400 a 750 pessoas, desenvolvendo ações de prevenção de doenças e promoção da saúde, por meio de atividades educativas no domicílio e na comunidade, sob supervisão competente (Brasil, 2002).

Esses componentes da equipe cadastram todos 
os domicílios da área de abrangência da unidade de saúde e assim identificam os indivíduos e as famílias que estão expostas a maiores riscos de adoecer ou morrer e que precisam de mais atenção, requerendo visitas domiciliárias com maior frequência. Assim, a visita domiciliária (VD) constitui o principal instrumento de trabalho dos ACS. O Ministério da Saúde recomenda que haja no mínimo uma visita mensal a cada domicílio da área de atuação do agente, havendo variações em função do estado de saúde de seus habitantes (Brasil, 2001).

De acordo com Takahashi e Oliveira (2001), a VD pode ser definida como uma ferramenta de intervenção na Saúde da Família, utilizada pelos integrantes da equipe para conhecer as condições de vida e de saúde das famílias sob sua responsabilidade.

Entretanto, para que a visita seja bem-sucedida e atinja seu objetivo, é fundamental que ela seja devidamente planejada, para que o agente aproveite melhor seu tempo e o tempo das pessoas que vai visitar. Além disso, é importante que tanto este profissional como o indivíduo ou a família visitada compreendam a finalidade dessa atividade.

Desse modo, o objetivo deste trabalho foi descrever a percepção de adultos e idosos em relação à visita domiciliária realizada pelo agente comunitário de saúde.

\section{Método}

Para atingir o objetivo proposto, optou-se pela realização de estudo descritivo, de abordagem qualitativa, definida por Minayo (2004) como aquele que se preocupa com um nível de realidade que não pode ser quantificado, trabalhando com o universo de significados, motivos, aspirações, crenças, valores e atitudes que, por sua vez, correspondem a um espaço mais profundo das relações, dos processos e dos fenômenos que não podem ser reduzidos à operacionalização de variáveis.

A pesquisa foi realizada em uma Unidade de Saúde da Família do município de Botucatu, que se localiza na região central do Estado de São Paulo e dista cerca de $235 \mathrm{~km}$ da capital paulista. Na ocasião do estudo, estavam cadastradas nessa unidade 3.541 pessoas, sendo que dessas, 246 eram idosas
Participaram desta pesquisa quatorze (14) adultos e idosos que atenderam aos critérios de inclusão previamente estabelecidos: possuir idade entre $18 \mathrm{e}$ 75 anos, fazer parte da área de abrangência da Unidade de Saúde da Família, concordar em participar e não apresentar déficit cognitivo que prejudique o pensamento, a orientação e a comunicação verbal.

Ressalta-se que, por se tratar de estudo qualitativo, a seleção da amostra considerou a variabilidade e qualidade dos depoimentos dos sujeitos entrevistados (Lefèvre e Lefèvre, 200o), de maneira a reconstituir a percepção de adultos e idosos em relação à visita domiciliária.

Buscando atender os preceitos éticos estabelecidos na Resolução nº 196/96 do Conselho Nacional de Saúde, que aprovou as diretrizes e normas regulamentadoras para pesquisas envolvendo seres humanos (Brasil, 1996), os dados foram coletados mediante parecer favorável do Comitê de Ética e Bioética da Faculdade Marechal Rondon - COEBE/FMR (processo $n^{\circ}$ o16/o7), durante o mês de maio de 2007. Após os participantes receberem informações em linguagem acessível sobre o objetivo, procedimentos (incluindo a gravação das entrevistas), garantia de esclarecimentos durante toda a pesquisa, liberdade de recusa ou de retirar seu consentimento a qualquer momento e garantia de sigilo, assinaram o Termo de Consentimento Livre e Esclarecido.

Como instrumentos para a coleta de dados foram utilizados o formulário sociodemográfico, com a finalidade de se obter dados individuais e familiares, como nome, sexo, idade, anos de aprovação escolar, ocupação, número de componentes da família e renda familiar mensal, e a entrevista semiestruturada, elaborada a partir de questões abertas referentes à percepção do participante sobre a visita do ACS: Como é para você receber a visita do agente? Como você vê a visita? Quais atividades são realizadas durante as visitas?

As entrevistas gravadas foram transcritas na íntegra. Após a leitura exaustiva, repetida e atenta das informações obtidas, os dados foram organizados tendo como base algumas figuras metodológicas da técnica do Discurso do Sujeito Coletivo (DSC), elaborado por Lefèvre e Lefèvre (2000):

- identificação das expressões-chave: constituídas por transcrições literais de parte dos depoimentos, 
que permitem o resgate do que é essencial no conteúdo discursivo dos segmentos em que se divide o depoimento;

- identificação das ideias centrais (IC): afirmações que permitem traduzir o essencial do conteúdo discursivo explicitado pelos sujeitos em seus depoimentos;

- construção do discurso do sujeito coletivo (DSC): a partir do agrupamento das convergências existentes entre as expressões-chave, reconstrói-se por meio de fragmentos de discursos individuais, tantos discursos-síntese quantos forem necessários, para expressar um dado pensar sobre o fenômeno. Ressalta-se que esses discursos, construídos com vários depoimentos reunidos num só discurso-síntese, serão apresentados como se o grupo falasse na primeira pessoa do singular.

\section{Resultados e Discussão}

\section{A caracterização dos participantes da pesquisa}

Para este estudo foram entrevistados 14 sujeitos, sendo 12 do sexo feminino $(85,71 \%)$ e apenas 2 do sexo masculino (14,29\%). A idade dos participantes variou entre 18 e 75 anos, sendo que $42,85 \%$ tinham entre 60 e 69 anos.

Em relação à escolaridade, pôde-se observar que os entrevistados apresentaram de o a 15 anos de aprovação escolar, sendo que $42,85 \%$ apresentaram de 1 a 4 anos de aprovação, 14,30\% apresentaram de 5 a 8 anos, 35,71 \% apresentaram de 9 a 11 anos e 7,14\% tinham 15 anos de aprovação escolar.

As ocupações predominantes entre os 14 participantes foram, respectivamente, donas de casa $(42,85 \%)$ e aposentados (35,71\%). As ocupações de professora, pensionista e empregada doméstica representaram 7,14 \% dos entrevistados, cada uma delas.

O número de componentes das famílias dos entrevistados variou de 1 a 7 sujeitos, sendo que a maioria era composta por 3 sujeitos (35,71\%).

Essas famílias viviam com renda familiar mensal que variou de $\mathrm{R} \$ 400,00$ a $\mathrm{R} \$ 4.000,00$ : $28,58 \%$ tinham renda entre R\$ 40o,oo e R\$ 60o,oo; 42,86\% tinham renda de R\$ 601,oo a R\$ 80o,oo; 14,28\% viviam com renda entre R\$ 801,oo e R\$ 1.00o,oo; 7,14\% tinham renda entre $\mathrm{R} \$ 1.001,00$ e $\mathrm{R} \$ 2.000,00$ e 7,14\% tinham renda de $\mathrm{R} \$ 4.000,00$ reais.

\section{0 discurso do sujeito coletivo}

\section{Tema A - Sentimentos e percepções em relação à visita e ao agente comunitário}

Esse tema sobre a percepção da visita domiciliária realizada pelo agente comunitário de saúde se refere aos sentimentos que adultos e idosos apresentam diante dessa prática. É formado pelas ideias centrais: "a percepção de que o número de visitas mensais é insuficiente", "gratidão e contentamento ao receber as visitas do agente comunitário" e "o desconhecimento do conteúdo do relatório".

IC 1 - A percepção de que o número de visitas mensais é insuficiente

Expressões-chave: demora para passar; devia passar mais vezes; demora bastante tempo para passar

Todos os entrevistados relataram receber a visita mensalmente, entretanto, apesar de não se constituir em uma questão específica para este estudo, a maior parte, demonstrou descontentamento com sua frequência, já que gostariam que as visitas fossem mais frequentes para que seus resultados de exames laboratoriais, por exemplo, fossem entregues mais rapidamente. Alguns dos entrevistados não mencionaram o número de vezes por mês que recebiam a visita, por referirem "demora" de uma visita para outra, conforme pode ser observado no DSC 1 :

DSC 1 - Olha, agora você me pegou... Não recebo a visita... só vai a menina do posto... Recebo na minha casa, na casa da minha nora [porque] eu moro na frente... mas não é assim uma vez por semana, às vezes passa de quinze em quinze dias, uma vez por mês... ele [agente comunitário de saúde] demora para passar... eu acho que ele devia passar mais vezes: por exemplo uma vez por semana, porque se passa uma vez por mês, às vezes a gente precisa fazer várias perguntas, a gente precisa de alguma coisa. Então acho que devia passar mais, várias vezes e não só uma vez por mês. Eu acho que ninguém reclamou, ninguém reclama nada, mas é que às vezes demora bastante tempo para passar... fica um tempão sem ir; até agora eu estou esperando o resultado do meu exame... eu fiz em abril o papa e não foram mais na minha casa, não foram avisar se deu alguma coisa... 
Inicialmente cabe mencionar um dado específico que nos chamou a atenção: algumas pessoas, apesar de reconhecerem o ACS como sendo da unidade de saúde, não estão familiarizadas com o termo, o que pôde ser evidenciado particularmente na fala de um dos sujeitos, quando questionado se recebia a visita do agente: "Não, só vai a menina do posto".

Sabe-se que os ACS são os maiores responsáveis pelas visitas domiciliares (Azeredo e col., 2007), embora haja a recomendação oficial que auxiliares ou técnicos de enfermagem, enfermeiros e médicos das equipes de saúde da família também realizem essa atividade, de acordo com o planejamento local.

Entretanto, de acordo com pesquisas realizadas por Ferraz e Aerts (2005), a grande maioria dos ACS considera impossível realizar as visitas em todas as casas mensalmente, tendo então que priorizar as famílias que mais necessitam de acompanhamento, como, por exemplo: puérperas, crianças e tuberculosos que estão em tratamento médico.

\section{IC - Gratidão e contentamento ao receber as visi- tas do agente comunitário}

Expressões-chave: gosto dele; fico contente; só tenho a agradecer; tem que agradecer

Os entrevistados relataram gostar de receber a visita do ACS, sobretudo pelo fato de sentirem-se sós ou de permanecerem sozinhos na maior parte do dia. Quando recebem a visita, têm a oportunidade de conversar e de fortalecer o vínculo com o ACS e sentem-se gratos com a atenção a eles dispensada. O DSC 2 ilustra esse resultado:

DSC 2 - Ah! Eu gosto dele, é muito educado, bonzinho... é sempre o mesmo que vai, nós somos conhecidos, quase vizinhos; eu o trato bem e ele me trata bem também. Eu gosto que a visita [o agente] vai lá em casa, ainda mais que eu fico o dia sozinho; minha vizinha que também é doente fica feliz quando vão lá; ela liga para mim e conversa "ah, [o agente] esteve aqui hoje" e eu fico contente porque é bom, ajuda a gente, eu só tenho a agradecer porque às vezes a gente tem alguma coisa ou também tem muitas pessoas que não vão ao posto porque estão com dor e aí a visita ajuda. Não é em todo momento que a gente está numa situação boa de saúde... às vezes a gente está meio "coiso" e se ele vai lá [no domicílio], já ajuda. É muito importante, é uma atenção que o posto dá para a gente então tem que agradecer.

Estas informações foram evidenciadas, sobretudo, junto aos pacientes idosos, possivelmente pelo fato de eles, além de se sentirem sós, não terem uma rede de suporte familiar tão fortalecida. Diante disso, os ACS também cumprem o importante papel de suporte e apoio tão necessário na velhice.

Um estudo realizado por Bezerra e colaboradores (2005), com o objetivo de analisar as principais concepções entre agentes comunitários referentes ao processo de envelhecimento, evidenciou que esses profissionais se reconhecem como protagonistas da atenção ao envelhecimento no contexto da atenção básica e sinalizou a necessidade de investir na formação de agentes capazes de lidar com os múltiplos aspectos do envelhecimento.

IC - $_{3} \mathrm{O}$ desconhecimento do conteúdo do relatório Expressões-chave: não sei o que ele escreve; acho que é o que eu respondo

Os entrevistados deste estudo desconhecem o teor das anotações que o ACS realiza durante a visita; têm a impressão que são pertinentes ao que relatam durante a VD, de acordo com o que pode ser observado no DSC 3:

DSC 3 - Ele mostra que tem uns papéis para anotar e escreve lá, mas eu não sei o que ele escreve... ele pergunta e depois escreve lá, entendeu? Ele entra, senta, conversa comigo e anota as coisas dele... acho que é o que eu respondo, mas daí já não sei... só sei que ele dá alguma coisa para a gente assinar e aí a gente assina.

Comumente, o ACS, ao retornar da VD para a unidade de saúde, elabora um relatório relatando a VD que deve ser anexado junto ao prontuário do usuário. Esse relatório é muito importante para que as informações coletadas cheguem aos outros membros da equipe, devendo ser claro, objetivo e sintético, apresentando uma sequência lógica das informações colhidas, observações e intervenções realizadas na visita (Takahashi e Oliveira, 2001).

Convém ressaltar que, a situação evidenciada na VD, sistematizada por meio do relatório, deve ser respaldada pelo principio ético da privacidade e da necessidade de sigilo dos profissionais (Fortes e Spinetti, 2004), ou seja, deve ser assegurado aos 
pacientes que as informações registradas serão compartilhadas apenas com a equipe de saúde, visando melhorar o cuidado oferecido. Entretanto, o conteúdo desses relatórios deveria ser de conhecimento dos pacientes; deveria ficar claro para eles o que foi registrado pelo ACS, antes que assinassem o documento.

Desse modo, seguindo preceitos éticos para essa atividade, esta pesquisa evidencia a necessidade de esclarecer corretamente ao sujeito entrevistado o teor das anotações realizadas durante a visita, assim, ele também pode sentir-se mais respeitado.

\section{Tema B - 0 reconhecimento das ações do agente comunitário}

Este é o segundo tema que engloba a percepção da visita domiciliária realizada pelo agente comunitário de saúde e se refere aos papéis desempenhados pelo ACS, na percepção dos adultos e dos idosos entrevistados. Congrega as idéias centrais: "o questionamento sobre o estado de saúde da família”, "as orientações para ir à unidade de saúde", "as orientações e o incentivo para o autocuidado" e "a verificação do uso da medicação, do controle da pressão arterial e do agendamento de consulta e exames".

\section{IC - O questionamento sobre o estado de saúde da família}

Expressões-chave: pergunta como está você e a família; pergunta dos filhos; quer saber se está bem de saúde

Os entrevistados relataram que os ACS, quando realizam as visitas, questionam sobre o estado de saúde de todos os membros da família, conforme ilustra o DSC 4:

DSC 4 - Ele pergunta tudo, como esta você, a família... pergunta dos meus filhos, pergunta se está em dia com a vacina se tem criança... quer saber se a gente está bem, se está bem de saúde e se está precisando de alguma coisa. Também pergunta como está a pressão da gente, se a gente está medindo "de acordo". Pergunta como que o médico receitou o remédio e depois pergunta como é que eu estou tomando, se tenho vindo na consulta... ele "pega no meu pé" e se a gente está doente ou precisando de alguma coisa do posto, ele vai lá, conversa com o médico e depois passa para a gente.
De acordo com a Portaria $\mathrm{n}^{0} 1886$ do Ministério da Saúde, o ACS deve desenvolver atividades de prevenção das doenças e promoção da saúde, através de VD e de ações educativas individuais e coletivas nos domicílios e na comunidade, sob supervisão e acompanhamento do enfermeiro (Brasil, 1997).

Nota-se que, nesta pesquisa, os participantes percebem que os ACS fazem questionamentos que visam identificar pontos passíveis de intervenções, como atraso na vacinação, controle da pressão arterial, uso regular de medicamento e comparecimento regular às consultas na unidade de saúde.

Desse modo, a partir desse levantamento, é possível conhecer o estado de saúde dos integrantes da família para melhor respaldar as ações de cuidado por parte da equipe de saúde, encaminhando, quando necessário, as demandas a outros profissionais.

\section{IC - As orientações para ir à unidade de saúde}

Expressões-chave: manda vir no posto; ele mesmo marca (consulta)

Os entrevistados reconheceram também, como sendo uma das atividades do ACS, o incentivo para que eles procurem a unidade de saúde, diante de situações que assim o exigem, de acordo com o apresentado no DSC 5:

DSC 5 - Ele manda eu vir no posto, fala que se precisar é para vir no posto e não ficar em casa, por exemplo, se eu estou com algum problema, com alguma dor, ele fala "vai no médico, vai passar na extra" [consulta não agendada]. Se a minha consulta estiver longe e eu estiver mal... quando eu estou doente, ele mesmo marca para mim e eu vou.

A atividade do ACS durante a VD envolvem e educação em saúde para a prevenção de complicações do estado de saúde, sobretudo com famílias de gestantes, crianças, idosos e pessoas em condições crônicas de saúde. Diante de problemas levantados durante a VD, é papel do ACS orientar o indivíduo a se dirigir à unidade de saúde para que passe por avaliação médica ou de enfermagem (Levy e col., 2004).

IC $_{6}$ - As orientações e o incentivo para o autocuidado

Expressões-chave: conversa direitinho; explica alguma coisa; dá a primeira orientação; incentiva 
para a caminhada e os passeios

Outra função do ACS reconhecida pelos entrevistados deste estudo foram as orientações, bem como o incentivo, pertinentes aos cuidados de saúde que podem ser desempenhados pelos próprios pacientes e seus familiares. Os entrevistados acreditam que essas orientações iniciais ajudam, mesmo que seja necessário recorrer à unidade de saúde. O DSC 6 representa essa percepção:

DSC 6 - Ele conversa direitinho, sempre me explica alguma coisa, fala o que eu tenho que fazer... às vezes a gente quer saber alguma coisa e pergunta para ele e ele comunica a gente, porque tem muita coisa aqui no posto que a gente não sabe e daí ele vai em casa e avisa; dá a primeira orientação é aí é mais fácil, a gente já vem orientado. Ele também fala para mim da pressão alta, da diabete, fala para mim da caminhada, para tomar os remédios direito... ele me incentiva para a caminhada e para os passeios.

Azeredo e colaboradores (2007) também ressaltam a importância das orientações fornecidas pelo ACS, já que seu estudo constatou que alguns usuários dos serviços de saúde relataram que, durante as visitas domiciliárias dos ACS, recebem importantes informações e orientações sobre os cuidados sanitários e que certamente proporcionam mudanças saudáveis de comportamento.

IC - Verificação do uso da medicação, do controle da pressão arterial e do agendamento de consulta e exames

Expressões-chave: ver o remédio que estou tomando; ver o cartão da pressão; ver o dia da consulta; exame para marcar

Os participantes do estudo reconhecem o papel do ACS no que diz respeito também ao controle da tomada da medicação, da pressão arterial e do agendamento de consultas e exames como os laboratoriais, prevenção do câncer ginecológico, de acordo com o constatado por meio do DSC 7 :

$\mathrm{DSC}_{7}$ - Ele pede para ver o remédio que eu estou tomando, o cartão da pressão para ver se está tudo certinho comigo, se preocupa. Também vê o cartão do posto, para ver se tem alguma consulta ou exame para fazer no posto, porque às vezes a consulta demora um pouco e aí eu esqueço tam- bém. Então ele vê o dia da consulta e perto do dia ele vai lá e me avisa. Às vezes leva um papelzinho assim... se tem consulta vem um papelzinho para a gente. Se tem exame para marcar ou para ver o resultado ele me traz aqui.

De acordo com a Política Nacional de Atenção Básica (Brasil, 2007), estão incluídas entre as atividades do ACS a integração da equipe de saúde com a população, o trabalho com a adscrição das famílias em território definido, o desenvolvimento de ações educativas junto às famílias, realização e atualização dos cadastros, orientação das famílias quanto à utilização dos serviços de saúde, desenvolvimento de atividades de promoção da saúde e prevenção de doenças e agravos e vigilância à saúde.

O discurso supracitado transparece a percepção da atividade de busca ativa, visto que o ACS, nas visitas domiciliárias, toma providências no sentido de garantir a manutenção da saúde e a prevenção de complicações decorrentes da doença.

Entretanto, essa associação da visita à possibilidade de o próprio ACS agendar consultas e entregar resultados de exames, ao mesmo tempo em que pode ampliar o acesso dos usuários que apresentam mais dificuldade em comparecer ao serviço de saúde, como, por exemplo, idosos, de acordo com Gomes e colaboradores (2009), prejudica o acompanhamento das famílias, possivelmente por fazer com que algumas pessoas se tornem mais acomodadas, no sentido de terem a expectativa de que essa função seja o objetivo principal da visita domiciliária.

\section{Considerações Finais}

Nos últimos anos, a ESF tem tido grande importância para a diminuição dos índices de morbimortalidade no Brasil. Assim, com seu crescimento, o controle dos agravos, bem como sua prevenção e ações de promoção da saúde, podem ser realizados por meio das visitas domiciliárias realizadas pela equipe da ESF, sobretudo aquelas realizadas pelos ACS.

Nesse contexto, a visita do ACS é uma atividade importante dentro da ESF, visto que ele possui vínculo contínuo com a clientela da área de abrangência de sua unidade.

De uma maneira geral, os usuários entrevistados nesta pesquisa demonstraram sentimentos e percep- 
ções em relação à visita e à figura do ACS. Apesar de os entrevistados sentirem-se satisfeitos e gratos diante da visita, o fato de perceberem a frequência mensal como insuficiente, mesmo que atenda à recomendação oficial, e de alegarem desconhecer o conteúdo das anotações realizadas pelo agente no momento da visita sinalizam a necessidade de o enfermeiro investir de maneira mais intensa em atividades educativas junto a esses profissionais, priorizando questões que envolvem os processos de comunicação. Com essa medida será possível otimizar, qualitativamente, a realização desta atividade.

Acredita-se que este estudo possibilitou avanço do conhecimento na área, visto que, para que o enfermeiro possa avaliar e propor possíveis melhorias em relação às visitas realizadas pelos ACS, é importante conhecer como a clientela tem percebido essa atividade, considerando o respeito ao princípio da participação popular sobre as questões envolvidas no processo saúde-doença, visando à consolidação e ao fortalecimento do SUS.

\section{Referências}

AZEREDO, C. M.; COTTA, R. M. M.; SCHOTT, M. Avaliação das condições de habitação e saneamento: a importância da vista domiciliar no contexto do Programa de Saúde da Família. Ciência \& Saúde Coletiva, Rio de Janeiro, n.12, n. 3 , p. 743-753, maio-jun. 2007.

BEZERRA, A. F. B.; ESPÍRITO SANTO, A. C. G; BATISTA FILHO, M. Concepções e práticas do agente comunitário na atenção à saúde do idoso. Revista de Saúde Pública, São Paulo, v. 39, n. 5, p. 8og-815, out. 2005 .

BRASIL. Ministério da Saúde. Política Nacional de Atenção Básica. Portaria n ${ }^{\circ}$ 648/GM de 28 de março de 2006. 4. ed. Brasília, DF: Ministério da Saúde, 2007. p. 9-55.

BRASIL. Lei $n^{\circ} 10.507$ de 10 de julho de 2002. Cria a profissão de Agente Comunitário de saúde e dá outras providências. Disponível em: <http://wwwo1o.dataprev.gov.br/sislex/ paginas/42/2002/10507.htm>. Acesso em: $19 \mathrm{fev}$. 2007.
BRASIL. Ministério da Saúde. Programa Agentes Comunitários de Saúde. PACS. Brasília, DF: Ministério da Saúde, 2001. 40 p.

BRASIL. Portaria n 1886/GM, de 18 de dezembro de 1997. Aprova as Normas e Diretrizes do Programa de Agentes Comunitários de Saúde e do Programa de Saúde da Família. Disponível em: <http://www.saude.sc.gov. br/PSF/PORTARIAS/Portaria\%2on1886\%20\%20original\%2018dez1997.doc>. Acesso em: 28 set. 2007.

BRASIL. Ministério da Saúde. Conselho Nacional de Saúde, Comissão Nacional de Ética em Pesquisa. Resolução $N^{o} 196$, de 10 de outubro de 1996. Diretrizes e normas regulamentadoras de pesquisas envolvendo seres humanos. Brasília: Ministério da Saúde, 1996.

FERRAZ, L.; AERTS, D. R. G. C. O cotidiano de trabalho do agente comunitário de saúde do PSF em Porto Alegre. Ciência \& Saúde Coletiva, Rio de Janeiro, v. 10, n. 2, p. 347-355, abr.-jun. 2005.

FORTES, P. A. C.; SPINETTI, S. R. $O$ agente comunitário de saúde e a privacidade das informações dos usuários. Cadernos de Saúde Pública, Rio de Janeiro, v. 20, n. 5, p. 1328-1333, set-out. 2004.

GOMES, K. O. et al. A práxis do Agente Comunitário de Saúde no contexto do Programa Saúde da Família: reflexões estratégicas. Saúde e Sociedade, São Paulo, v. 18, n. 4, p.744-755, out. dez. 2009.

LEFÈVRE, F., LEFÈVRE, A. M. C. Os novos instrumentos no contexto da pesquisa qualitativa. In: LEFÈVRE, F., LEFÈVRE, A. M. C; TEIXEIRA, J. J. V. (org.). O discurso do sujeito coletivo: uma nova abordagem metodológica em pesquisa qualitativa. Caxias do Sul: EDUCS, 2000. p. 11-35.

LEVY, F. M.; MATOS, P. E. S.; TOMITA, N. E. Programa de agentes comunitários de saúde: a percepção de usuários e trabalhadores de saúde. Cadernos de Saúde Pública, Rio de Janeiro, v. 20, n.1, p. 197-203, jan.-fev. 2004.

MINAYO, M. C. S. O desafio do conhecimento: pesquisa qualitativa em saúde. São Paulo: HUCITEC, 2004. 
SILVA, L. O processo de conviver com um idoso dependente sob a perspectiva do grupo familiar. 2007. 166 f. Dissertação (Mestrado em Enfermagem) - Departamento de Enfermagem Psiquiátrica e Ciências Humanas, Escola de Enfermagem da Universidade de São Paulo, Ribeirão Preto, 2007.

SILVA, L.; BOUSSO, R. S.; GALERA, S. A. F. Aplicação do Modelo Calgary para avaliação de famílias de idosos na prática clínica. Revista Brasileira de Enfermagem, Brasília, v. 62, n. 4, p. 530-534, jul-ago, 2009.

SISSON, M. C. Considerações sobre o Programa Saúde da Família e a promoção de maior equidade nas políticas de saúde. Saúde e Sociedade, São Paulo, v. 16, n. 3, p. 85-91, set.-dez. 2007.

TAKAHASHI, R. F.; OLIVEIRA, M. A. C. A visita domiciliária no contexto da saúde da família. In: BRASIL. Instituto para o Desenvolvimento da Saúde. Universidade de São Paulo. Ministério da Saúde. Manual de enfermagem. Brasília: Ministério da Saúde, 2001. (Série A. Normas e Manuais Técnicos, n. 135). p. 43-46. 